\title{
Knowledge, attitudes, and practices related to the COVID-19 pandemic among Bangladeshi youth: a web-based cross-sectional analysis
}

\author{
Rajon Banik ${ }^{1}$ (D) $\cdot$ Mahmudur Rahman ${ }^{1} \cdot$ Md. Tajuddin Sikder ${ }^{1} \cdot$ Quazi Maksudur Rahman ${ }^{1} \cdot$ Mamun Ur Rashid Pranta $^{1}$
}

Received: 13 June 2020 / Accepted: 20 November 2020 / Published online: 16 January 2021

(C) Springer-Verlag GmbH Germany, part of Springer Nature 2021, corrected publication 2021

\begin{abstract}
Aim This study aimed to assess knowledge, attitudes, and practices (KAP) toward COVID-19 among youth in Bangladesh. Subject and methods A cross-sectional survey was conducted from 5 May to 25 May 2020. People aged between 18 and 35 years were approached via social media to complete an online questionnaire that consisted of socio-demographic information and KAP toward COVID-19. Descriptive statistics, t-tests, one-way analysis of variance (ANOVA), and logistic regression analyses were conducted.

Results Out of 707 survey participants, $57.1 \%$ were male, the majority were students (60.3\%), aged 24-29 years (61.5\%), having a bachelor's degree (57\%), having family income 25,000-50,000 BDT (40.5\%) and living in urban areas (64.4\%). Participants gathered information on COVID-19 mostly through social media (70.4\%). Overall, 61.2\% had adequate knowledge with 78.9\% having a positive attitudes toward COVID-19 and only 51.6\% had good practices. Most (86.8\%) of the participants were confident that COVID-19 will be successfully controlled and Bangladesh was handling the COVID-19 health crisis well (84.2\%). Only $75.2 \%$ of participants always washed their hands with soap or hand-sanitizer, and $70.6 \%$ wore a mask when going outside the home. Factors associated with adequate knowledge were being female, having a master's degree and above, and living in an urban area $(p<0.05)$. Participants having adequate knowledge of COVID-19 had higher likelihood of positive attitudes (OR: 6.41, 95\% CI $=2.34-25.56, p<0.001)$ and good practices (OR: 8.93, 95\% CI $=3.92-38.42, p<0.001)$.

Conclusion The findings highlight the need for tailored education programs for COVID-19 which incorporates consideration of associated factors to improve the level of public knowledge, attitudes, and practices.
\end{abstract}

Keywords COVID-19 $\cdot$ Knowledge $\cdot$ Attitude $\cdot$ Practice $\cdot$ Youth $\cdot$ Bangladesh

\section{Introduction}

Coronavirus disease 2019 (COVID-19) has evolved into a serious public health concern due to a novel human coronavirus, commonly recognized as severe acute respiratory syndrome coronavirus 2 (SARS-CoV-2), which has been declared as a pandemic (Cucinotta and Vanelli 2020; Lake 2020). Since its origins in the Huanan seafood market in Wuhan, province of Hubei, China at the end of 2019, this novel virus has gained intense attention by spreading rapidly

Rajon Banik

rajonbanik.phi.ju@gmail.com

1 Department of Public Health and Informatics, Jahangirnagar University, Savar, Dhaka 1342, Bangladesh to the rest of the world ( $\mathrm{Li}$ et al. 2020). This situation was announced as a public health emergency of international concern (PHEIC) by the World Health Organization (WHO) on 30 January 2020 (WHO 2020a). COVID-19 is extremely contagious and can even be transmitted by respiratory droplets (coughs or sneezes) in contact with an infected person (CDC 2020). Up to $80 \%$ of COVID-19 cases have minor flu-like symptoms, fever, fatigue, discomfort, shortness of breath, and can be recovered without medical assistance (Huang et al. 2020). Particularly the elderly and those with preexisting medical conditions (such as cardiovascular disease, diabetes, chronic respiratory disease, and cancer) are at increased risk of severity (Tian et al. 2020). As such, there is no antiviral curative remedy or vaccine (to date) to cope with this pandemic (Sahin 2020), the WHO recommends that the best approach to deter and curb the spread of COVID-19 is to be knowledgeable of the disease, its symptoms, modes of 
transmission and precautions, such as hand hygiene, social distancing, respiratory etiquette, and wearing a mask (WHO 2020b).

In Bangladesh, on 8 March 2020 the Institute of Epidemiology, Disease Control and Research (IEDCR) proclaimed the first-ever confirmed case of COVID-19 (Banik et al. 2020), since then the number of cases started to spik and 975 deaths out of 71,675 confirmed cases have been reported as of 8 June 2020 (IEDCR 2020). To safeguard citizens, Bangladesh's government has taken unprecedented protective and precautionary actions and instituted a regional lockdown from 26 March 2020 (Kamruzzaman and Sakib 2020). Furthermore, all government and non-government entities, along with print and digital media, undertook massive advertising regarding COVID-19 to raise the awareness of the general public. However, evidence from numerous media reports upholds that a considerable number of people do not adequately follow these instructions, thus exacerbating the COVID19 situation in Bangladesh (Banik et al. 2020). Evidence suggests that, for such measures to be effective, public adherence is essential, which is affected by their knowledge, attitudes, and practices (KAP) toward COVID-19 (Ajilore and Atakiti 2017). Studies carried out during the SARS outbreak in 2003 suggest that knowledge and attitudes concerning infectious diseases are linked with serious misconceptions and panic among the public, which may disrupt further efforts to prevent the spread of disease (Tao 2003; Person et al. 2004). The KAP study regarding COVID-19 conducted in Hubei, China, concealed that public attitudes to obedience to government measures to combat the epidemic were significantly influenced by the level of knowledge about COVID-19 (Zhong et al. 2020). More knowledge was also found to be correlated with more optimistic attitudes toward COVID-19 preventive practices (Azlan et al. 2020; Zhong et al. 2020). In Bangladesh, a KAP study showed that a large proportion of people had limited knowledge of COVID-19 transmission and onset of symptoms and had positive perceptions of COVID-19 (Farhana 2020). Another Bangladeshi study found that despite $54-87 \%$ of respondents having access to good knowledge, the attitude and practices were not impressive mainly because of poor knowledge, nonscientific, and orthodox religious belief (Haque et al. 2020).

Furthermore, specifically among young people, there is no KAP study of COVID-19 available, although people between the ages of $21-40$ account for about $50 \%$ of positive cases in Bangladesh (WHO 2020c). We therefore aimed at assessing the KAP among youth during the rapid transmission phase of the pandemic in Bangladesh. This study is also expected to assist policymakers in designing suitable preventive approaches specifically targeting vulnerable groups for alleviating the burden of COVID19 in Bangladesh.

\section{Methods}

\section{Study design and setting}

A cross-sectional study was carried out from 5 May to 25 May 2020, among youth in Bangladesh through a webbased survey because it was not feasible to do a communitybased national sampling survey during the governmentimposed lockdown in Bangladesh. Eligibility criteria to participate in the survey were to be youth (18-35 years) (Ministry of Youth and Sports 2017; Liang et al. 2020), being Bangladeshi, a social media user, understanding the study purpose, and willingness to voluntary participation.

\section{Data collection procedure}

Data collection was performed via a structured questionnaire designed for the Google survey tool (Google Forms). The link generated from the Google Form was shared randomly as an invitation of participation to the public through social media groups (i.e., Facebook, WhatsApp) and also personally shared with the researcher's contact list. The first page of the questionnaire contained a brief introduction to the study's background, objective, eligibility criteria, declaration of confidentially, and anonymity and informed consent of each participant involved asking whether or not they wanted to participate in this study. Participants must respond positively for further proceeding with the self-reporting questionnaire that consisted of (i) socio-demographic information; (ii) knowledge about COVID-19; (iii) attitudes toward COVID-19; and (iv) practices toward COVID-19. For the questionnaire, Cronbach's alpha is 0.74 , suggesting the questionnaire is a legitimate and accurate tool for evaluating the purpose of the study.

\section{Sampling method}

The sample size was calculated using the following equation:

$n=\frac{z^{2} p q}{d^{2}} ; n=\frac{1.96^{2} \times 0.5 \times(1-0.5)}{0.05^{2}}=384.16 \approx 384$

Here,

$n$ = number of samples

$z=1.96(95 \%$ confidence level $)$

$p=$ prevalence estimate $(0.5)$

$q=(1-p)$

$d=$ Precession of the prevalence estimate $(0.05)$. 
The minimum required sample size calculated for this study was 384 . However, 707 participants were recruited to ensure the strength of the study. A total of 728 eligible participants were approached using a convenient sampling technique, and 707 completed the survey questionnaire, with a 97.3\% response rate, and were taken for final analysis.

\section{Measures}

Socio-demographic data of the participants were obtained through closed-ended questions involving their age, gender, educational level, marital status, occupation, monthly family income, the number of family members, place of residence, and division. Monthly family income was categorized into three classes: < 25,000 Bangladeshi Taka (BDT), 25,000$50,000 \mathrm{BDT}$, and $>50,000 \mathrm{BDT}$.

Participant's knowledge about COVID-19 was assessed using 13 items which were adapted from previous research (Azlan et al. 2020; Zhong et al. 2020). These 13 items comprised clinical presentations (items 1-4), transmission routes (items 5-8), and prevention and control (items 9-13) of COVID-19 with "true," "false," or "not sure" response options to these items. Each correct response to a knowledge item has been assigned 1 point, while 0 points have been assigned to each incorrect/not sure response. For knowledge items, the total score ranged from 0 to 13 , with a higher score indicating adequate knowledge about COVID-19. Bloom's cut-off of $80 \%$ ( $\geq 10.4$ ) was used to determine adequate knowledge (Kaliyaperumal 2004). The attitude section included five items, and the responses were assessed using a 3-point Likert scale "disagree," "not sure," and "agree" each weighing 1 to 3, respectively. The practice section consisted of five items that were adapted from WHO recommended practices for prevention of COVID-19 transmission, and the responses of each item were assessed with a 3-point Likert scale "never," "occasionally," and "always," each weighing 1 to 3 , respectively. Participant's average attitude and practice score of $\geq 2.4$ was set as a cut-off value for the positive attitude and good practice toward COVID-19, respectively (Olum et al. 2020).

\section{Data management and analysis}

Fully completed questionnaires were extracted from Google Forms and exported to Microsoft Excel 2010 for cleaning and coding. The cleaned data was exported to Statistical Package for Social Sciences (SPSS) version 25 software. Data analysis consisted of descriptive statistics, including frequency distribution, percentage, and computing mean scores. As applicable, the association between the mean scores and the sociodemographic characteristics of the participants was analyzed using a t-test or one-way analysis of variance (ANOVA). To identify related factors with the response binary logistic regression analysis was applied and the significance level was set at 0.05 (two-tailed).

\section{Results}

A total of 707 participants completed the survey questionnaire (response rate $=97.3 \%$ ) and participated in this study with a mean age of 25.03 (SD 4.26) years. The majority of the participants were male $(n=404,57.1 \%)$, unmarried $(n=506$, $71.61 \%), 554(78.4 \%)$ had at least a bachelor's degree, and the rest of the participants had an education level of higher secondary or below. Among the participants, 426 (60.3\%) were students and 127 (17.9\%) were employed either with the government or a private company. About $40 \%$ of participants reported having a monthly family income between 25,000-50,000 BDT. Most of the participants were from an urban area $(n=455,64.4 \%)$ in Dhaka division $(n=319$, $45.1 \%$ ). A detail of the socio-demographic characteristics of the participants is shown in Table 1. Social media such as Facebook was the main source of knowledge about COVID19 among participants $(n=498,70.4 \%)$ followed by news media (e.g., news channels, newspapers) (66.3\%), and internet (e.g., health organization's website) (58.7\%; Fig. 1).

\section{Knowledge}

The mean COVID-19 knowledge score for participants was 8.5 (SD: 2.6 range $0-13$ ). Participant's overall correct answer rate of this knowledge test was between 30.7 to $94.6 \%$. Approximately $61.2 \%$ of the participants scored $80 \%$ or more and were considered having adequate knowledge, and 38.8\% had inadequate knowledge (Fig. 2). A higher proportion of the participants $(n=646,91.4 \%)$ identified common clinical symptoms of COVID-19, and wearing a face mask as an effective way to prevent transmission of COVID-19 ( $n=632$, 89.4\%; Table 2). In addition, they recognized that people should avoid going to crowded places and avoid taking public transportation $(n=629,89.0 \%)$. However, noticeable confusion was found among participants regarding the mode of transmission of COVID-19, and only $51.5 \%$ of participants correctly reported that the COVID-19 virus is airborne, and very few $(n=306,43.3 \%)$ were able to respond correctly when asked if eating and touching wild animals could result in infection. Participant's knowledge scores significantly differed across age-groups, genders, education levels, monthly family incomes, and residence places $(p<0.05$; Table 3$)$. Regression analysis revealed factors associated with adequate knowledge of the participants and found that female participants had higher odds of having adequate knowledge (vs. male, OR: $2.75,95 \% \mathrm{CI}=1.82-3.45, p<0.001)$. Similarly, participants who had a master's degree and above (vs. secondary and blow, OR: $2.52,95 \% \mathrm{CI}=1.35-4.67, p<0.01)$ and 
Table 1 Socio-demographic characteristics of the participants $(n=707)$

\begin{tabular}{|c|c|c|}
\hline Characteristic & Frequency $(n)$ & Percentage $(\%)$ \\
\hline \multicolumn{3}{|l|}{ Age (years) } \\
\hline $18-23$ & 147 & 20.8 \\
\hline $24-29$ & 435 & 61.5 \\
\hline 30 or more & 125 & 17.7 \\
\hline \multicolumn{3}{|l|}{ Gender } \\
\hline Male & 404 & 57.1 \\
\hline Female & 303 & 42.9 \\
\hline \multicolumn{3}{|l|}{ Marital status } \\
\hline Unmarried & 506 & 71.6 \\
\hline Married & 201 & 28.4 \\
\hline \multicolumn{3}{|l|}{ Education level } \\
\hline Bachelor's degree & 403 & 57.0 \\
\hline Master's degree and above & 151 & 21.4 \\
\hline Higher secondary & 92 & 13.0 \\
\hline Secondary and below & 61 & 8.6 \\
\hline \multicolumn{3}{|l|}{ Occupation } \\
\hline Student & 426 & 60.3 \\
\hline Govt./private job & 127 & 17.9 \\
\hline Business & 86 & 12.2 \\
\hline Unemployed & 68 & 9.6 \\
\hline \multicolumn{3}{|l|}{ Monthly family income } \\
\hline$<25,000 \mathrm{BDT}$ & 191 & 27.0 \\
\hline $25,000-50,000$ BDT & 286 & 40.5 \\
\hline$>50,000 \mathrm{BDT}$ & 230 & 32.5 \\
\hline \multicolumn{3}{|l|}{ No of family member } \\
\hline Less than 5 & 329 & 46.5 \\
\hline Between 5 and 7 & 260 & 36.8 \\
\hline More than 7 & 118 & 16.7 \\
\hline \multicolumn{3}{|l|}{ Place of residence } \\
\hline Urban & 455 & 64.4 \\
\hline Rural & 252 & 35.6 \\
\hline \multicolumn{3}{|l|}{ Divisional classification } \\
\hline Dhaka division & 319 & 45.1 \\
\hline Chattogram division & 207 & 29.3 \\
\hline Rangpur division & 127 & 18.0 \\
\hline Others $^{\mathrm{a}}$ & 54 & 7.6 \\
\hline
\end{tabular}

${ }^{a}$ Mymensingh division, Barisal division, and Sylhet division BDT $=$ Bangladeshi Taka

lived in an urban area (vs. rural, OR: $3.02,95 \% \mathrm{CI}=2.12$ $4.01, p<0.001$ ) had higher odds of having adequate knowledge regarding COVID-19 (Table 4).

\section{Attitude}

When participants were asked question regarding attitudes on COVID-19, we found that a majority of the participants had a positive attitude toward COVID-19 ( $n=558,78.9 \%$; Fig. 2$)$ with a mean attitude score of 2.7 (SD: 0.3). Approximately $87 \%(n=614)$ of the participants agreed that COVID-19 would successfully be controlled, and the rate of reporting "disagree" and "not sure" was $4.2 \%$ and $8.9 \%$, respectively. When participants were asked whether Bangladesh was handling the COVID-19 health crisis well, most of the participants $(n=$ $595,84.2 \%$ ) agreed with this statement with rates of disagreement and uncertainty at $5.8 \%$ and $10 \%$, respectively. However, $55.3 \%(n=391)$ believed that COVID-19 is a deadly disease when asked about the severity of the disease. Even so, participants were optimistic that self-awareness is necessary to remain free from COVID-19 with an $80.1 \%$ agreement (Fig. 3). A statistically significant association between attitude and socio-demographic variables such as age groups, marital status, education level, and place of residence $(p<0.05$, Table 3) was found. Participant in age group 30 years or more (vs. $18-23$ years, OR: $2.00,95 \% \mathrm{CI}=1.18-2.78, p<0.01$ ), with monthly family income $>50,000$ BDT (vs. $<25,000$ BDT, OR: $1.50,95 \% \mathrm{CI}=1.01-2.23, p<0.05$ ), and having adequate knowledge (vs. inadequate, OR: $6.41,95 \% \mathrm{CI}=$ 2.34-25.56, $p<0.001$ ) were more likely to have a positive attitude (Table 4).

\section{Practices}

In terms of practices toward COVID-19 among participants, we found that $75.2 \%(n=532)$ always washed their hands with soap or hand-sanitizer thoroughly and up to $70.6 \%$ ( $n=499$; Fig. 4$)$ always wore a mask when going outside the home in recent days. However, $33.9 \%(n=240)$ and $14.6(n=130)$ of participants reported "occasionally" and "never" maintained safe distance with people (3 feet) when going outside the home. Meanwhile, only $62.1 \%$ $(n=439)$ of participants avoided going to any crowded place, and the rate of reporting "occasionally" and "never" was $30.0 \%$ and $7.9 \%$, respectively. The overall mean practice score of the participants was 2.5 (SD: 0.4), and only $51.6 \%$ of participants ( $n=365$; Fig. 2 ) had a good practice regarding COVID-19. Participant's mean practice score was significantly different in terms of gender, education level, monthly family income, and place of residence $(p<0.05$; Table 3$)$. Regression analysis showed that female gender (vs. male, OR: 3.23, 95\% CI $=2.13-6.57$, $p<0.01$ ), education of "master's degree and above" (vs. secondary and below, OR: $1.44,95 \% \mathrm{CI}=1.03-2.02$, $p<0.05$ ), occupation of "govt./private job" (vs. business, OR: $4.82,95 \% \mathrm{CI}=1.45-17.23, p<0.01)$, residing in urban area (vs. rural, OR: $5.42,95 \% \mathrm{CI}=2.32-18.71, p<0.001$ ), and having adequate COVID-19 knowledge (vs. inadequate, OR: $8.93,95 \% \mathrm{CI}=3.92-38.42, p<0.001$ ) were more likely to have good practices (Table 4 ). 
Fig. 1 Sources of knowledge regarding COVID-19 among participants (multiple response question)

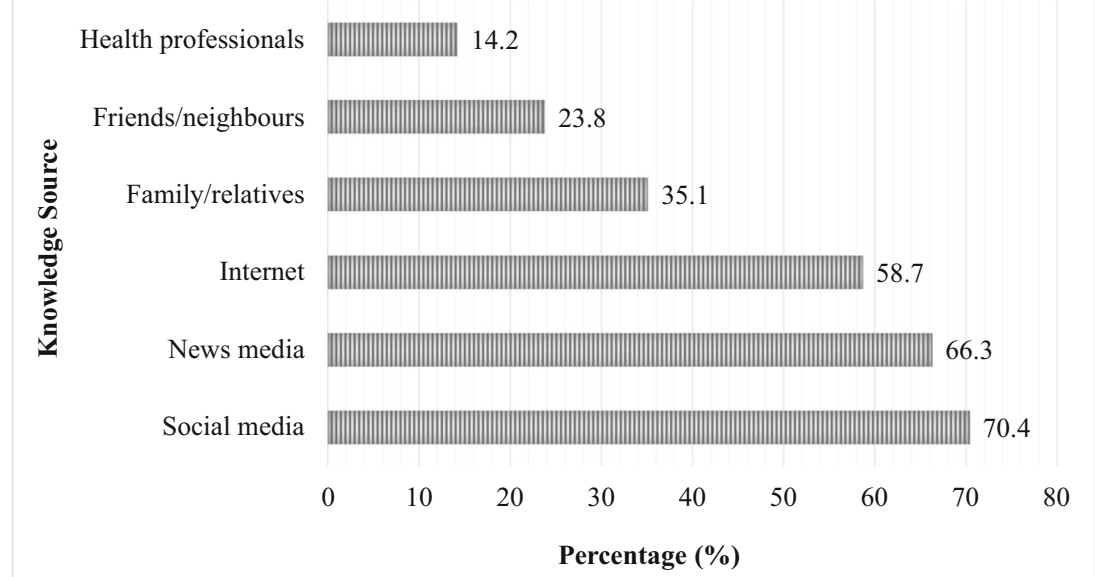

\section{Discussion}

In the present study, we evaluated knowledge, attitudes, and practices toward COVID-19 among youth in Bangladesh. The study found that approximately six in every ten $(61.2 \%)$ participants had adequate knowledge about COVID-19. This knowledge score, however, is higher than that recorded among Bangladeshi general people (33.0\%) (Paul et al. 2020) but far lower than the COVID-19 knowledge score among Pakistani (75.5\%) and Malaysian (80.5\%) people (Azlan et al. 2020; Salman et al. 2020). Moreover, significantly high COVID-19 knowledge has also been recorded in studies conducted among Chinese (90\%) (Zhong et al. 2020) and US residents (80\%)
(Clements 2020). The low knowledge score regarding COVID-19 in this study has its roots partly in the participant's low exposure to government-stipulated information or advertising regarding COVID-19 since the outbreak began. Furthermore, the lack of severity in terms of reported cases and death from COVID-19 makes Bangladeshi residents unwilling to rigorously know about this infectious disease. This study also identified that the majority of the study participants access knowledge regarding COVID-19 mainly through social media such as Facebook, which is analogous with a recent COVID-19 study conducted by Farhana (2020). This finding is also justified by the fact that a vast majority of Bangladeshi youth rely on the internet and social media in their regular
Fig. 2 Level of knowledge, attitudes, and practices toward COVID-19 among the participants

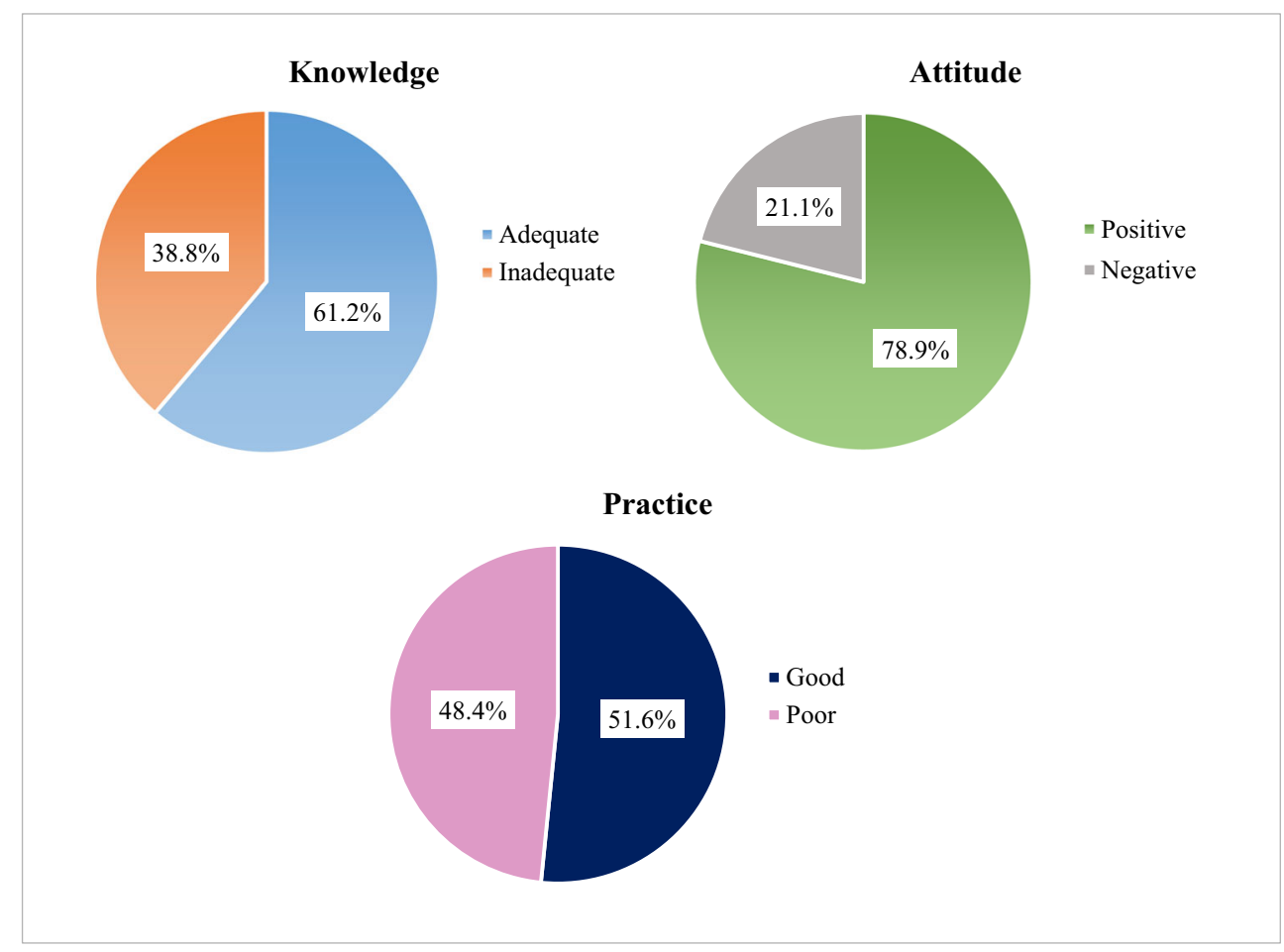


Table 2 Knowledge about COVID-19 among the participants $(n=707)$

\begin{tabular}{|c|c|c|c|}
\hline Knowledge Items & $\begin{array}{l}\text { True; } n \\
(\%)\end{array}$ & $\begin{array}{l}\text { False; } n \\
(\%)\end{array}$ & $\begin{array}{l}\text { Not sure; } n \\
(\%)\end{array}$ \\
\hline The major clinical symptoms of COVID-19 are fever, fatigue, dry cough, and myalgia. (True) & $646(91.4)$ & $32(4.5)$ & $29(4.1)$ \\
\hline $\begin{array}{l}\text { Unlike the common cold, stuffy nose, runny nose, and sneezing are less common in persons infected with } \\
\text { COVID-19. (True) }\end{array}$ & $339(47.9)$ & $248(35.1)$ & $120(17.0)$ \\
\hline $\begin{array}{l}\text { There currently is no effective cure for COVID-19, but early symptomatic and supportive treatment can help most } \\
\text { patients recover from the infection. (True) }\end{array}$ & $519(73.4)$ & $59(8.4)$ & $129(18.2)$ \\
\hline $\begin{array}{l}\text { Not all persons with COVID- } 2019 \text { will develop severe cases. Only those who are elderly and have chronic } \\
\text { illnesses are more likely to be in severe cases. (True) }\end{array}$ & $617(87.3)$ & $51(7.2)$ & 39 (5.5.) \\
\hline Eating or touching wild animals would result in the infection with COVID-19. (False) & $259(36.6)$ & $306(43.3)$ & $142(20.1)$ \\
\hline Persons with COVID-19 cannot transmit the virus to others if they do not have a fever. (False) & $98(13.9)$ & $571(80.8)$ & $38(5.3)$ \\
\hline COVID-19 can spread via respiratory droplets of infected individuals. (True) & $586(82.9)$ & $78(11.0)$ & $43(6.1)$ \\
\hline The virus of COVID-19 is airborne. (True) & $364(51.5)$ & $269(38.0)$ & $74(10.5)$ \\
\hline Ordinary residents can wear face masks to prevent infection with COVID-19. (True) & $632(89.4)$ & $50(7.1)$ & $25(3.5)$ \\
\hline It is not necessary for children and young adults to take measures to prevent infection with COVID-19. (False) & $120(17.0)$ & $532(75.2)$ & $55(7.8)$ \\
\hline $\begin{array}{l}\text { To prevent the infection by COVID-19, individuals should avoid going to crowded places and avoid taking public } \\
\text { transportations. (True) }\end{array}$ & $629(89.0)$ & $61(8.6)$ & $17(2.4)$ \\
\hline $\begin{array}{l}\text { Isolation and treatment of people who are infected with COVID-19 are effective ways to reduce the spread of the } \\
\text { virus. (True) }\end{array}$ & $616(87.1)$ & $62(8.8)$ & $29(4.1)$ \\
\hline $\begin{array}{l}\text { People who have contact with someone infected with COVID-19 should be immediately isolated for } 14 \text { days. } \\
\text { (True) }\end{array}$ & $574(81.2)$ & 81 (11.5) & $52(7.3)$ \\
\hline
\end{tabular}

lifestyle and this has increased by $15-20 \%$ during the lockdown initiative amid COVID-19 (Hossain 2020).

A substantial number of sociodemographic factors significantly affect participant's knowledge scores such as agegroups, genders, education levels, monthly family incomes, and places of residence, which were quite similar to a recent study conducted in Bangladesh by Hossain et al. (2020). Regression analysis found participant's adequate knowledge was dominated by factors such as gender, education, and place of residence. Female participants were more likely to have adequate knowledge. This finding was surprisingly similar to a recent study among urban and rural residents in China by Yue et al. (2020). Higher education level was significantly associated with having adequate knowledge, which can be justified by previous studies conducted in Iran and Bangladesh (Erfani et al. 2020; Farhana 2020). This shows a substantial educational gap, possibly reflecting substandard information to the public and dissemination concerning COVID-19. Thus, customizing the information obtained regarding the epidemic by health authorities as well as other news agencies are required to tackle the multifaceted complexity of drivers contributing to inadequate knowledge.

The present study found that a large majority of participants were optimistic and showed a positive attitude $(78.9 \%)$ toward COVID-19. Approximately $87 \%$ of participants were reported that the virus can be successfully controlled, and $84.2 \%$ of participants were confident that the Bangladeshi government was handling the health crisis very well. A high level of positive attitude among participants regarding COVID-19 was also found in studies conducted among people in Malaysia and Saudi-Arabia (Al-Hanawi et al. 2020; Azlan et al. 2020). Positive attitudes and high confidence in the control of COVID-19 can be interpreted by the Bangladesh government's unprecedented response in taking stringent control and precautionary steps including the lockdown, and suspension of all domestic and international flights, prayer at mosques, the closing of all offices and educational institutions to safeguard citizens from COVID-19 (WHO 2020d). Evidence from the SARS epidemic in China also showed high confidence among residents (70.1-88.9\%) that SARS can be successfully controlled and a recent KAP study by Zhong et al. (2020) on COVID-19 also found a positive attitude among $90.8 \%$ of Chinese people. Participant's attitudes differ by age, marital status, education, and place of residence. In contrast, a study in Thailand found participants' attitudes were not affected by age, gender, experience, and job/occupation (Srichan et al. 2020). Regression analysis revealed sociodemographic factors such as older age, monthly family income $>50,000$ BDT, and adequate knowledge were associated with more positive attitudes regarding COVID-19, overall recapitulating previous findings by Ferdous et al. (2020). Participants' positive attitude was significantly correlated with the level of COVID-19 knowledge, and similarly, a study among Chinese citizens observed that high COVID-19 scores were positively aligned with less possibility of "disagreement" and "unsure" responses to attitude questions (Zhong et al. 2020). 


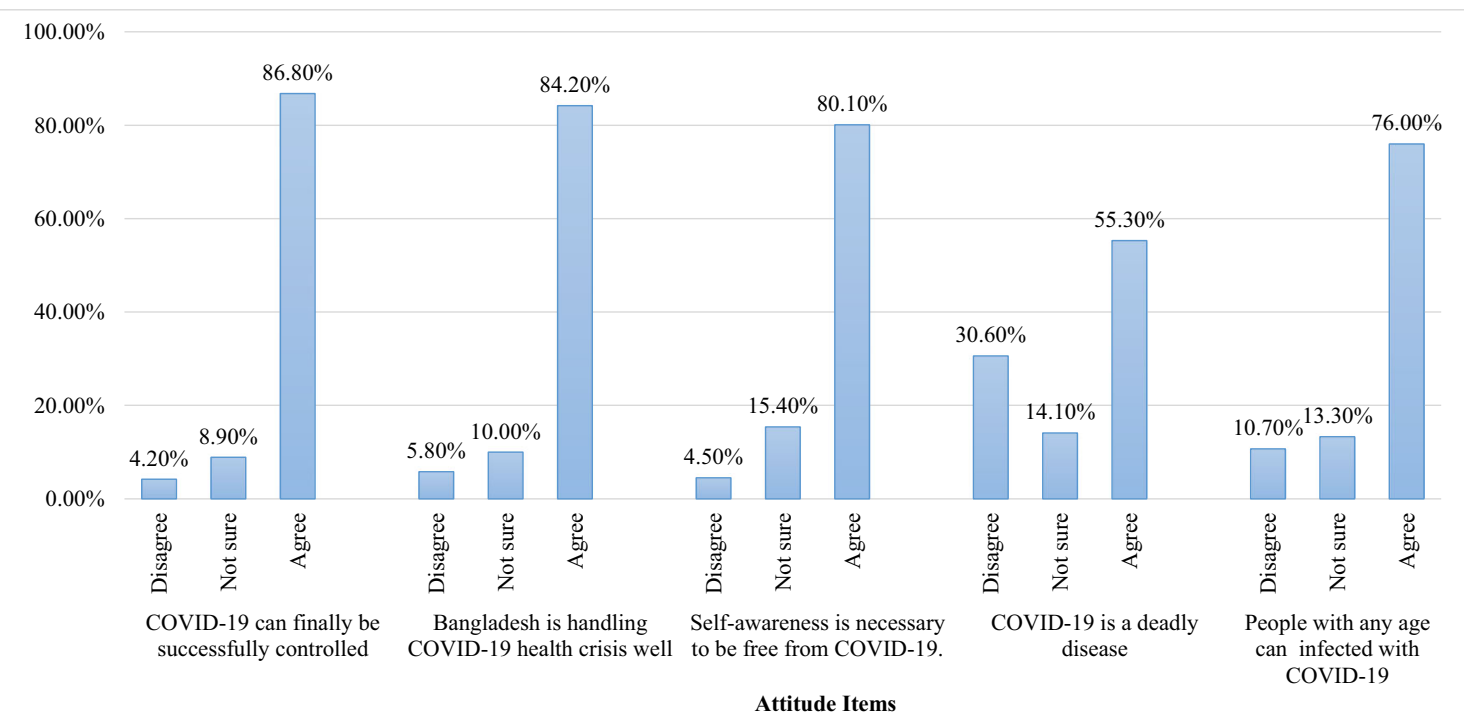

Fig. 3 Attitudes of the participants toward COVID-19 $(n=707)$

Although attitudes toward COVID-19 were optimistic, the present study still exhibits a notable proportion (48.4\%) of the youth in Bangladesh who did not have good preventive practices to COVID-19. In terms of practicing hand hygiene, approximately three fourth of the participants $(75.2 \%)$ stated that they always wash their hands with soap or hand sanitizer, which was remarkably similar to the findings of other studies (Al-Hanawi et al. 2020; Olum et al. 2020), except for a study in Thailand, which found $54.8 \%$ did not regularly use soap during washing of hands (Srichan et al. 2020). Approximately $90 \%$ of participants responded positively to wearing masks when going outside the home. This finding is similar to previous KAP studies regarding COVID-19 (Erfani et al. 2020; Rahman and Sathi 2020), but contradictory to a study conducted among Malaysian people, which found $51.2 \%$ of participants reported wearing a face mask when going out in public (Azlan et al. 2020). Unfortunately, still, a significant proportion of participants are reluctant to appropriate preventive practices in terms of avoiding going to any crowded place in contrast to findings among Nepalese people, which showed approximately $94 \%$ of the participants had avoided visiting any crowded place (Asraf et al. 2020). This vast variety in findings is due to the fact that although the Bangladeshi government imposed a nationwide lockdown and social

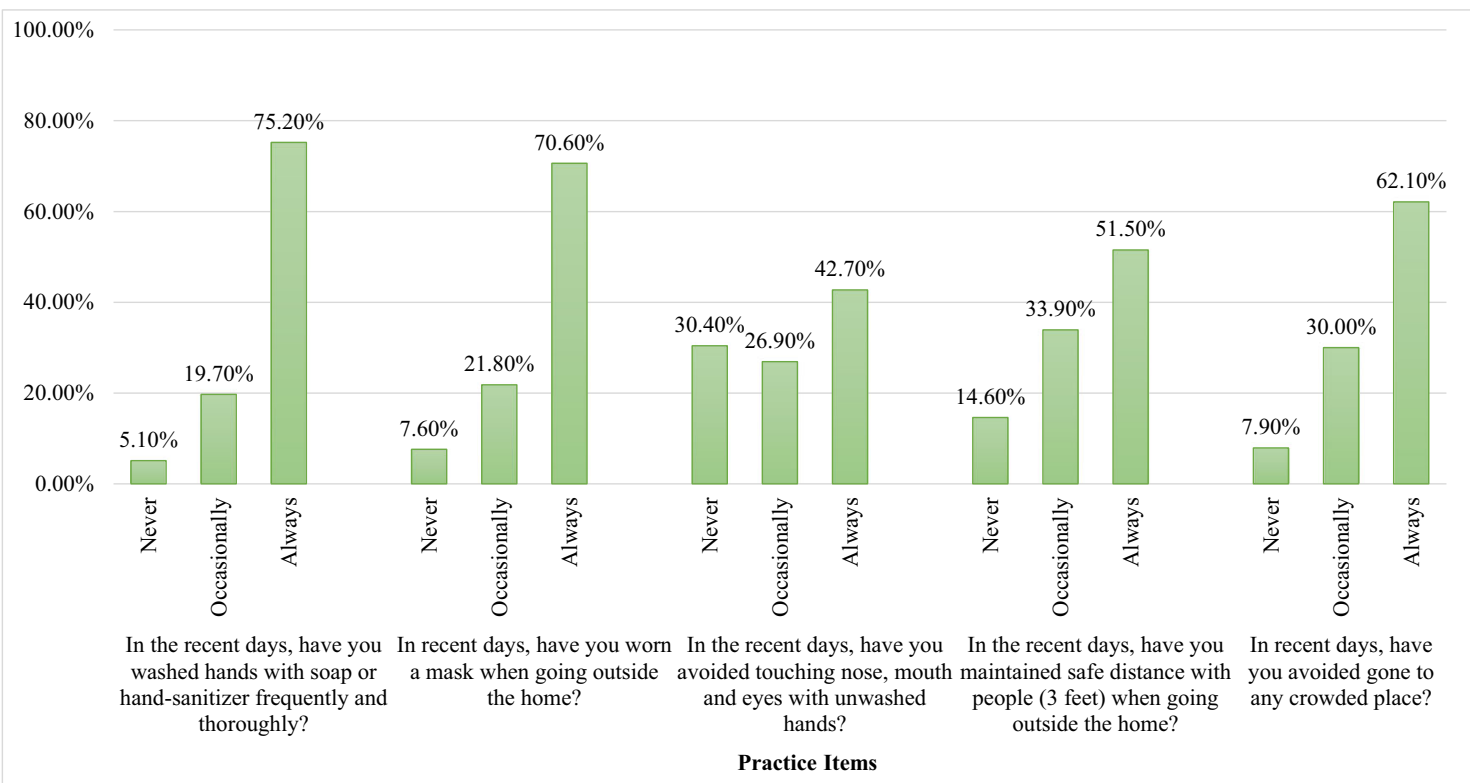

Fig. 4 Practices of the participants toward COVID-19 $(n=707)$ 
Table 3 Association between socio-demographic characteristics and mean KAP score

\begin{tabular}{|c|c|c|c|c|c|c|}
\hline \multirow[t]{2}{*}{ Variable } & \multicolumn{2}{|l|}{ Knowledge } & \multicolumn{2}{|l|}{ Attitude } & \multicolumn{2}{|l|}{ Practice } \\
\hline & Mean \pm SD & $\mathrm{t} / \mathrm{F}$ test & Mean \pm SD & $\mathrm{t} / \mathrm{F}$ test & Mean \pm SD & $\mathrm{t} / \mathrm{F}$ test \\
\hline \multicolumn{7}{|l|}{ Age (years) } \\
\hline $18-23$ & $8.14 \pm 2.68$ & $3.865^{*}$ & $2.61 \pm 0.34$ & $4.825 * *$ & $2.44 \pm 0.36$ & 1.709 \\
\hline $24-29$ & $8.46 \pm 2.57$ & & $2.70 \pm 0.32$ & & $2.51 \pm 0.37$ & \\
\hline 30 or more & $9.00 \pm 2.48$ & & $2.81 \pm 0.29$ & & $2.47 \pm 0.36$ & \\
\hline \multicolumn{7}{|l|}{ Gender } \\
\hline Male & $8.16 \pm 2.73$ & $14.834 * * *$ & $2.68 \pm 0.32$ & 0.584 & $2.20 \pm 0.34$ & $5.269 * * *$ \\
\hline Female & $8.91 \pm 2.33$ & & $2.70 \pm 0.33$ & & $2.87 \pm 0.39$ & \\
\hline \multicolumn{7}{|l|}{ Marital status } \\
\hline Unmarried & $8.67 \pm 2.50$ & 0.567 & $2.42 \pm 0.36$ & $3.235^{*}$ & $2.46 \pm 0.36$ & 2.232 \\
\hline Married & $8.55 \pm 2.75$ & & $2.69 \pm 0.32$ & & $2.51 \pm 0.38$ & \\
\hline \multicolumn{7}{|l|}{ Education level } \\
\hline Bachelor's degree & $8.48 \pm 2.56$ & $4.179 * *$ & $2.71 \pm 0.34$ & $5.346^{* *}$ & $2.55 \pm 0.37$ & $3.234 *$ \\
\hline Master's degree and above & $9.01 \pm 2.29$ & & $2.81 \pm 0.32$ & & $2.71 \pm 0.34$ & \\
\hline Higher secondary & $8.07 \pm 2.77$ & & $2.54 \pm 0.35$ & & $2.38 \pm 0.36$ & \\
\hline Secondary and below & $7.84 \pm 2.99$ & & $2.33 \pm 0.34$ & & $2.29 \pm 0.35$ & \\
\hline \multicolumn{7}{|l|}{ Occupation } \\
\hline Student & $8.53 \pm 2.58$ & 0.982 & $2.70 \pm 0.32$ & 0.651 & $2.51 \pm 0.36$ & 0.475 \\
\hline Govt./private job & $8.69 \pm 2.59$ & & $2.67 \pm 0.30$ & & $2.47 \pm 0.35$ & \\
\hline Business & $8.28 \pm 2.57$ & & $2.64 \pm 0.34$ & & $2.45 \pm 0.35$ & \\
\hline Unemployed & $8.10 \pm 2.67$ & & $2.69 \pm 0.33$ & & $2.46 \pm 0.39$ & \\
\hline \multicolumn{7}{|l|}{ Monthly family income } \\
\hline$<25,000 \mathrm{BDT}$ & $8.12 \pm 2.82$ & $3.573 *$ & $2.66 \pm 0.34$ & 0.447 & $2.21 \pm 0.36$ & $4.254 * *$ \\
\hline $25,000-50,000$ BDT & $8.48 \pm 2.56$ & & $2.69 \pm 0.30$ & & $2.42 \pm 0.37$ & \\
\hline$>50,000 \mathrm{BDT}$ & $8.80 \pm 2.43$ & & $2.69 \pm 0.31$ & & $2.68 \pm 0.34$ & \\
\hline \multicolumn{7}{|l|}{ No of family member } \\
\hline Less than 5 & $8.41 \pm 2.61$ & 1.097 & $2.67 \pm 0.32$ & 1.057 & $2.49 \pm 0.35$ & 0.727 \\
\hline Between 5 and 7 & $8.67 \pm 2.40$ & & $2.71 \pm 0.30$ & & $2.42 \pm 0.37$ & \\
\hline More than 7 & $8.29 \pm 2.91$ & & $2.68 \pm 0.32$ & & $2.44 \pm 0.39$ & \\
\hline \multicolumn{7}{|l|}{ Place of residence } \\
\hline Urban & $8.89 \pm 2.34$ & $18.864 * * *$ & $2.71 \pm 0.30$ & $7.046 * *$ & $2.54 \pm 0.35$ & $9.783 * * *$ \\
\hline Rural & $7.76 \pm 2.78$ & & $2.64 \pm 0.35$ & & $2.36 \pm 0.36$ & \\
\hline \multicolumn{7}{|l|}{ Divisional classification } \\
\hline Dhaka division & $8.61 \pm 2.48$ & 1.856 & $2.69 \pm 0.32$ & 0.186 & $2.47 \pm 0.37$ & 0.039 \\
\hline Chattogram division & $8.53 \pm 2.43$ & & $2.68 \pm 0.33$ & & $2.48 \pm 0.36$ & \\
\hline Rangpur division & $8.40 \pm 2.78$ & & $2.67 \pm 0.31$ & & $2.48 \pm 0.35$ & \\
\hline Others $^{\mathrm{a}}$ & $8.36 \pm 3.06$ & & $2.69 \pm 0.33$ & & $2.49 \pm 0.36$ & \\
\hline
\end{tabular}

${ }^{a}$ Mymensingh division, Barisal division, and Sylhet division

$S D=$ Standard deviation

$* p<0.05 ; * * p<0.01 ; * * * p<0.001$

distancing measures, Bangladeshi youth showed negligence to obey rules because of their inadequate knowledge regarding the high infectivity of the virus that causes COVID-19, which can be easily transmitted between people via invisible respiratory droplets. Another underlying reason may be that Bangladeshi youth feel less susceptible to COVID-19 as stated by WHO compared to children and older people (Tian et al. 2020). Factors that interplay with inappropriate preventive practices were male gender, occupation of "business", education level of "secondary and below", residing in a rural area, and having inadequate COVID-19 knowledge. This study reveals an obvious fact that male participants had 
Table 4 Results of logistic regression analysis on factors associated with adequate knowledge, positive attitudes, and good practices toward COVID-19

\begin{tabular}{|c|c|c|c|c|c|c|}
\hline \multirow[t]{2}{*}{ Variable } & \multicolumn{2}{|c|}{ Adequate knowledge } & \multicolumn{2}{|c|}{ Positive attitude } & \multicolumn{2}{|c|}{ Good practice } \\
\hline & $n(\%)$ & OR $(95 \% \mathrm{CI})$ & $n(\%)$ & OR $(95 \% \mathrm{CI})$ & $n(\%)$ & OR $(95 \% \mathrm{CI})$ \\
\hline \multicolumn{7}{|l|}{ Age (years) } \\
\hline $18-23$ & $81(18.7)$ & Ref. & $102(18.4)$ & Ref. & $65(17.8)$ & Ref. \\
\hline $24-29$ & $270(62.4)$ & $1.33(0.91-1.95)$ & $352(63.1)$ & $1.21(0.92-2.14)$ & $217(59.5)$ & $1.19(0.74-1.93)$ \\
\hline 30 or more & $82(18.9)$ & $1.55(0.95-2.54)$ & $104(18.5)$ & $2.00(1.18-2.78)^{* *}$ & $83(22.7)$ & $1.03(0.77-1.39)$ \\
\hline \multicolumn{7}{|l|}{ Gender } \\
\hline Male & $208(48.0)$ & Ref. & $243(43.5)$ & Ref. & $155(42.5)$ & Ref. \\
\hline Female & $225(52.0)$ & $2.75(1.82-3.45)^{* * *}$ & $315(56.5)$ & $0.87(0.61-1.26)$ & $210(57.5)$ & $3.23(2.13-6.57)^{* *}$ \\
\hline \multicolumn{7}{|l|}{ Marital status } \\
\hline Unmarried & $325(75.1)$ & $1.28(0.64-2.97)$ & 399 (71.5) & $1.28(0.66-1.47)$ & $257(70.4)$ & $1.13(0.81-1.56)$ \\
\hline Married & $108(24.9)$ & Ref. & $159(28.4)$ & Ref. & $108(29.6)$ & Ref. \\
\hline \multicolumn{7}{|l|}{ Education level } \\
\hline Bachelor's degree & $245(56.6)$ & $1.41(0.82-2.41)$ & $319(57.2)$ & $1.52(0.72-3.21)$ & $212(58.1)$ & $1.06(0.58-1.73)$ \\
\hline Master's degree and above & $111(25.6)$ & $2.52(1.35-4.67)^{* *}$ & $117(21.0)$ & $0.91(0.58-1.42)$ & $74(20.3)$ & $1.44(1.03-2.02)^{*}$ \\
\hline Higher secondary & $45(10.4)$ & $0.87(0.45-1.66)$ & $70(12.5)$ & $0.84(0.49-1.43)$ & 47 (12.9) & $0.95(0.49-1.81)$ \\
\hline Secondary and below & $32(7.4)$ & Ref. & $52(9.3)$ & Ref. & $32(8.8)$ & Ref. \\
\hline \multicolumn{7}{|l|}{ Occupation } \\
\hline Student & $264(61.0)$ & $1.21(0.72-2.04)$ & $342(61.3)$ & $0.87(0.43-1.79)$ & $218(59.7)$ & $2.35(1.01-5.67)$ \\
\hline Govt./private job & $82(18.9)$ & $1.36(0.74-2.48)$ & $98(17.6)$ & $1.06(0.56-1.99)$ & $64(17.5)$ & $4.82(1.45-17.23)^{* *}$ \\
\hline Unemployed & $48(11.1)$ & $0.94(0.49-1.79)$ & $64(11.5)$ & $0.75(0.35-1.62)$ & $48(13.2)$ & $0.92(0.31-2.86)$ \\
\hline Business & $39(9.0)$ & Ref. & $54(9.7)$ & Ref. & $35(9.6)$ & Ref. \\
\hline \multicolumn{7}{|l|}{ Monthly family income } \\
\hline$<25,000 \mathrm{BDT}$ & $107(24.7)$ & Ref. & $146(26.2)$ & Ref. & $94(25.8$ & Ref. \\
\hline $25,000-50,000$ BDT & $175(40.4)$ & $1.29(0.83-2.02)$ & $231(41.4)$ & $1.24(0.85-1.79)$ & $149(40.8)$ & $1.12(0.78-1.62)$ \\
\hline$>50,000 \mathrm{BDT}$ & $151(34.9)$ & $1.14(0.72-1.80)$ & $181(32.4)$ & $1.50(1.01-2.23)^{*}$ & $122(33.4)$ & $3.7(0.83-16.81)$ \\
\hline \multicolumn{7}{|l|}{ No of family member } \\
\hline Less than 5 & $197(45.5)$ & $1.02(0.67-1.57)$ & $255(45.7)$ & $1.07(0.65-1.76)$ & $182(49.9)$ & $1.37(0.89-2.09)$ \\
\hline Between 5 and 7 & $166(38.3)$ & $1.21(0.781 .89)$ & $213(38.2)$ & $1.41(0.83-2.39)$ & $127(34.8)$ & $1.05(0.684-1.63)$ \\
\hline More than 7 & $70(16.7)$ & Ref. & $90(16.1)$ & Ref. & $56(15.3)$ & Ref. \\
\hline \multicolumn{7}{|l|}{ Place of residence } \\
\hline Urban & $320(73.9)$ & $3.02(2.12-4.01)^{* * *}$ & $375(67.2)$ & $1.23(0.98-2.56)$ & $272(74.5)$ & $5.42(2.32-18.71)^{* * * *}$ \\
\hline Rural & $113(26.1)$ & Ref. & $183(32.8)$ & Ref. & $93(25.5)$ & Ref. \\
\hline \multicolumn{7}{|l|}{ Divisional classification } \\
\hline Dhaka division & $197(45.5)$ & $1.21(1.16-2.82)$ & $256(45.9)$ & $1.26(0.65-2.55)$ & $166(45.5)$ & $0.81(0.45-1.44)$ \\
\hline Chattogram division & 137 (31.6) & $1.12(0.98-2.99)$ & $160(28.7)$ & $1.08(0.53-2.18)$ & $104(28.5)$ & $0.75(0.41-1.37)$ \\
\hline Rangpur division & $76(17.6)$ & $1.56(1.83-2.53)$ & $101(18.1)$ & $1.23(0.57-2.63)$ & $64(17.5)$ & $0.75(0.39-1.43)$ \\
\hline Others $^{\mathrm{a}}$ & $23(5.3)$ & Ref. & $41(7.3)$ & Ref. & $31(8.5)$ & Ref. \\
\hline \multicolumn{7}{|l|}{ Knowledge level } \\
\hline Adequate & - & - & $345(61.8)$ & $6.41(2.34-25.56)^{* * *}$ & $222(60.8)$ & $8.93(3.92-38.42)^{* * *}$ \\
\hline Inadequate & & & $213(38.2)$ & Ref. & $143(39.2)$ & Ref. \\
\hline
\end{tabular}

${ }^{a}$ Mymensingh division, Barisal division, and Sylhet division

$O R=$ Odds ratio

$C I=$ Confidence interval

$* p<0.05 ; * * p<0.01 ; * * * p<0.001$ 
potentially inappropriate practices and were at high risk to get COVID-19. Such findings demonstrate the value of optimizing the COVID-19 knowledge of Bangladeshi residents through education programs explicitly engaging certain demographic groups, which can also contribute to improvements in their attitudes and practices toward COVID-19.

\section{Conclusion}

In summary, the present research was able to have an extensive evaluation of KAP toward COVID-19 among Bangladeshi youth. Our findings have shown that a considerable number of youth in Bangladesh are adequately knowledgeable regarding COVID-19 and have shown a positive attitude, but are insensitive to appropriate preventive measures, which can be alarming. Effective health education campaigns aimed at enhancing knowledge of COVID-19 are therefore desperately needed to encourage people to have an even more positive mindset and maintain appropriate preventive practices.

\section{Limitations of the study}

This study has several limitations. First, this study followed a cross-sectional study design that cannot establish causal inferences. Second, self-reporting interviews were used to collect data instead of face-to-face interviews, which is prone to social desirability and declarative memory biases. Third, this study used an online survey with a convenience sample through the networks of the researchers and disseminated through different social media platforms (Facebook, WhatsApp). As a result, there is a possibility of bias as underprivileged populations may not have been able to participate in the study, thereby the survey was restricted to only those with internet access, and consequently unlikely to represent an accurate reflection of all Bangladeshi youth.

Acknowledgments The authors gratefully acknowledge all the participants of this study who willingly presented their valuable time and conscientiously provided thoughtful and attentive responses during the uncomfortable COVID-19 pandemic. Furthermore, the authors are also grateful to the people who supported the collection of data online and highly appreciate the contribution of Md. Safaet Hossain Sujan, Dipjoy Saha Ananda, Md. Ashraful Islam Robin, Huaad Haq Himel, and Mahfuzur Rahman.

Authors' contribution Rajon Banik: Conceptualization, methodology, investigation, data acquisition, data curation, formal analysis, Writing original draft, editing, validation. Mahmudur Rahman: Investigation, writing - review and editing, validation. Md. Tajuddin Sikder: Supervision, investigation, writing - review and editing, validation. Quazi Maksudur Rahman: Data acquisition, methodology, validation. Mamun Ur Rashid Pranta: Data acquisition, data curation, validation.

\section{Compliance with ethical standards}

Ethical approval This research was approved by the Biosafety, Biosecurity, and Ethical review board of the Jahangirnagar University, Savar, Dhaka-1342, Bangladesh (Ref. No: BBEC, JU/ M 2020/COVID19/(11)2).

Informed consent All participants provided their informed consent to participate in the study after being informed about the purpose of the study. Furthermore, the participants were given no economic motivation, and anonymity was maintained to ensure data confidentiality and reliability.

Conflict of interest The authors declare that they have no potential conflict of interest in the publication of this research.

\section{References}

Ajilore K, Atakiti I (2017) College students ' knowledge , attitudes and adherence to public service announcements on Ebola in Nigeria : suggestions for improving future Ebola prevention education programmes. Health Educ J 76:1-13. https://doi.org/10.1177/ 0017896917710969

Al-Hanawi MK, Angawi K, Alshareef N et al (2020) Knowledge, attitude and practice toward COVID-19 among the public in the Kingdom of Saudi Arabia : a cross-sectional study. Front Public Health 8:1-10. https://doi.org/10.3389/fpubh.2020.00217

Asraf H, Garima T, Singh BM et al (2020) Knowledge, attitudes , and practices towards COVID-19 among Nepalese residents : a quick online cross-sectional survey. Asian J Med Sci 11:6-11. https://doi. org/10.3126/ajms.v11i3.28485

Azlan AA, Hamzah MR, Sern TJ et al (2020) Public knowledge, attitudes and practices towards COVID-19: a cross-sectional study in Malaysia. PLoS One 15:e0233668. https://doi.org/10.1371/journal. pone. 0233668

Banik R, Rahman M, Sikder MT, Gozal D (2020) COVID-19 in Bangladesh: public awareness and insufficient health facilities remain key challenges. Public Health 183:50-51. https://doi.org/10. 1016/j.puhe.2020.04.037

Centers for Disease Control and Prevention (2020) How COVID-19 spreads. https://www.cdc.gov/coronavirus/2019-ncov/preventgetting-sick/how-covid-spreads.html. Accessed 23 May 2020

Clements JM (2020) Knowledge and behaviors toward COVID-19 among us residents during the early days of the pandemic: crosssectional online questionnaire. J Med Internet Res 22:1-11. https:// doi.org/10.2196/19161

Cucinotta D, Vanelli M (2020) WHO declares COVID-19 a pandemic. Acta Biomed 91:157-160. https://doi.org/10.23750/abm.v91i1. 9397

Erfani A, Shahriarirad R, Ranjbar K, Mirahmadizadeh A, Moghadami M (2020) Knowledge, attitude and practice toward the novel coronavirus (COVID-19) outbreak: a population-based survey in Iran. Bull World Health Organ. https://doi.org/10.2471/BLT.20.251561

Farhana K (2020) Knowledge and perception towards novel coronavirus (COVID-19) in Bangladesh. Int Res J Bus Soc Sci 6:76-79. https:// doi.org/10.2139/ssm.3578477

Ferdous MZ, Islam MS, Sikder MT et al (2020) Knowledge, attitude, and practice regarding COVID-19 outbreak in Bangladesh: an onlinebased cross-sectional study. PLoS One 15:e0239254. https://doi. org/10.1371/journal.pone.0239254

Haque T, Hossain KM, Bhuiyan MMR et al (2020) Knowledge, attitude and practices (KAP) towards COVID-19 and assessment of risks of infection by SARS-CoV-2 among the Bangladeshi population : an 
online cross sectional survey. Res Sq. https://doi.org/10.21203/rs.3. rs- $24562 / \mathrm{v} 1$

Hossain I (2020) Mobile operators struggling to cope with rise in data consumption. In: Financ Express. https://thefinancialexpress.com. $\mathrm{bd} /$ trade/mobile-operators-struggling-to-cope-with-rise-in-dataconsumption-1587611418. Accessed 6 May 2020

Hossain MA, Hossain KMA, Walton LM, et al (2020) Knowledge, attitudes, and fear of COVID-19 during the rapid rise period in Bangladesh. medRxiv 2020.06.17.20133611. https://doi.org/10. 1101/2020.06.17.20133611

Huang C, Wang Y, Li X et al (2020) Clinical features of patients infected with 2019 novel coronavirus in Wuhan, China. Lancet 395:497506. https://doi.org/10.1016/S0140-6736(20)30183-5

Institute of Epidemiology Disease Control and Research (IEDCR) (2020) Covid-19 Status for Bangladesh. https://www.iedcr.gov.bd/. Accessed 4 Aug 2020

Kaliyaperumal K (2004) Guideline for conducting a knowledge, attitude and practice (KAP) study. AECS Illum 4:7-9

Kamruzzaman M, Sakib SN (2020) Bangladesh imposes total lockdown over COVID-19. In: Anadolu Agency. https://www.aa.com.tr/en/ asia-pacific/bangladesh-imposes-total-lockdown-over-covid-19/ 1778272. Accessed 5 Jun 2020

Lake MA (2020) What we know so far: COVID-19 current clinical knowledge and research. Clin Med J R Coll Physicians London 20:124-127. https://doi.org/10.7861/clinmed.2019-coron

Li Q, Guan X, Wu P et al (2020) Early transmission dynamics in Wuhan, China, of novel coronavirus-infected pneumonia. N Engl J Med 382:1199-1207. https://doi.org/10.1056/NEJMoa2001316

Liang L, Ren H, Cao R, et al (2020) The effect of COVID-19 on youth mental health. Psychiatr Q 91:841-852. https://doi.org/10.1007/ s11126-020-09744-3

Ministry of Youth and Sports (2017) National Youth Policy 2017. In: Govt People's Repub Bangladesh. https://dyd.portal.gov.bd/sites/default/ files/files/dyd.portal.gov.bd/policies/21e565b2_252f_4f80_bfce 31a1cb33163d/DraftEnglishVersionofNationalYouthPolicy2017(1). pdf. Accessed 8 Jun 2020

Olum R, Chekwech G, Wekha G et al (2020) Coronavirus Disease-2019: knowledge, attitude, and practices of health Care Workers at Makerere University Teaching Hospitals, Uganda. Front Public Health 8:1-9. https://doi.org/10.3389/fpubh.2020.00181

Paul A, Sikdar D, Hossain MM et al (2020) Knowledge, attitudes, and practices toward the novel coronavirus among Bangladeshis: implications for mitigation measures. PLoS One 15:e0238492. https:// doi.org/10.1371/journal.pone.0238492

Person B, Sy F, Holton K et al (2004) Fear and stigma : the epidemic within the SARS outbreak. Emerg Infect Dis 10:358-363. https:// doi.org/10.3201/eid1002.030750

Rahman A, Sathi NJ (2020) Knowledge attitude and preventive practices toward Covid-19 among Bangladeshi internet users. Electron J Gen Med 17:em245. https://doi.org/10.29333/ejgm/8223
Sahin AR (2020) 2019 novel coronavirus (COVID-19) outbreak: a review of the current literature. Eurasian J Med Oncol 4:1-7. https:// doi.org/10.14744/ejmo.2020.12220

Salman M, Ul Mustafa Z, Asif N et al (2020) Knowledge, attitude and preventive practices related to COVID-19 among health professionals of Punjab province of Pakistan. J Infect Dev Ctries 14: 707-712. https://doi.org/10.3855/jidc. 12878

Srichan P, Apidechkul T, Tamornpark R et al (2020) Knowledge, attitudes and preparedness to respond to COVID-19 among the border population of northern Thailand in the early period of the pandemic: a cross-sectional study. WHO South-East Asia J Public Health 9: 118-125. https://doi.org/10.4103/2224-3151.294305

Tao N (2003) An analysis on reasons of SARS-induced psychological panic among students. J Anhui Inst Educ 21:78-79

Tian S, Hu N, Lou J et al (2020) Characteristics of COVID-19 infection in Beijing. J Inf Secur 80:401-406. https://doi.org/10.1016/j.jinf.2020. 02.018

World Health Organization (WHO) (2020a) Statement on the second meeting of the international health regulations (2005) emergency committee regarding the outbreak of novel coronavirus (2019nCoV). In: Interim Guid. WHO, Geneva, Swizerland. https:// www.who.int/news-room/detail/30-01-2020-statement-on-thesecond-meeting-of-the-international-health-regulations-(2005)emergency-committee-regarding-the-outbreak-of-novelcoronavirus-(2019-ncov). Accessed 5 Jun 2020

World Health Organization (WHO) (2020b) Infection prevention and control during health care when novel coronavirus ( $\mathrm{nCoV}$ ) infection is suspected. Interim guidance, WHO, Geneva. https:// www.who.int/publications/i/item/10665-331495

World Health Organization (WHO) (2020c) Coronavirus disease (COVID-2019): situation report. WHO, Bangladesh, p 6. https:// www.who.int/bangladesh/emergencies/coronavirus-disease-(covid19)-update/coronavirus-disease-(covid-2019)-bangladesh-situationreports

World Health Organization (WHO) (2020d) Coronavirus disease (COVID-2019): Situation Report No. \# 6. WHO, Bangladesh. https://www.who.int/docs/default-source/searo/bangladesh/covid19-who-bangladesh-situation-reports/who-ban-covid-19-sitrep-06. pdf?sfvrsn=36254da0 6

Yue S, Zhang J, Cao M, Chen B (2020) Knowledge, attitudes and practices of COVID-19 among urban and rural residents in China: a cross-sectional study. J Community Health:3-8. https://doi.org/10. 1007/s10900-020-00877-x

Zhong BL, Luo W, Li HM et al (2020) Knowledge, attitudes, and practices towards COVID-19 among chinese residents during the rapid rise period of the COVID-19 outbreak: a quick online crosssectional survey. Int J Biol Sci 16:1745-1752. https://doi.org/10. $7150 /$ ijbs. 45221

Publisher's note Springer Nature remains neutral with regard to jurisdictional claims in published maps and institutional affiliations. 